\title{
A construção de usinas hidrelétricas e as disputas assimétricas para usos diversos dos espaços ambientais
}

\begin{abstract}
The construction of hydroelectric plants and asymmetric disputes for various uses of environmental spaces
\end{abstract}

Marcos Cristiano Zucarelli ${ }^{1}$

Resumo: A partir dos anos de 1970, o pressuposto do paradigma do desenvolvimento sustentável fundamentado na crença de compatibilidade entre desenvolvimento econômico e preservação ambiental passou a ser incorporado por diversos segmentos sociais. Guiado pelo "efeito de naturalização" desta crença, o conceito de desenvolvimento sustentável surge como uma nova ideologia/utopia à continuidade das premissas desenvolvimentistas do modelo capitalista de produção. Contudo, esta ideia "compatibilizadora" apresenta inúmeras contradições, dentre as quais destacamos a apropriação assimétrica da natureza e os processos de injustiça ambiental através da construção de hidrelétricas. Baseado no estudo de caso da construção da usina hidrelétrica de Irapé, no Vale do Jequitinhonha, Minas Gerais, este trabalho almeja demonstrar que a disputa por "espaços ambientais", surge como reflexo do conflito entre várias vertentes pela apropriação da natureza e repercute na ocupação desigual destes "espaços", gerando externalidades sociais e injustiças ambientais. Ancorado na lógica plural de apropriação da natureza,

\footnotetext{
1 Professor no curso de Direito da Universidade FUMEC (www.fumec.br). Doutorando em Antropologia Social (PPGAN/UFMG). Mestre em Sociologia pela Universidade Federal de Minas Gerais. Pesquisador colaborador no Grupo de Estudos em Temáticas Ambientais (GESTA/UFMG). Tem experiência na área de Sociedade e Meio Ambiente, com ênfase nos seguintes temas: saneamento ambiental, desenvolvimento sustentável, licenciamento ambiental, biocombustíveis, conflitos ambientais, deslocamentos compulsórios decorrentes de grandes projetos de infraestrutura e criação de unidades de conservação.
}

Latitude, Vol. 9, nº 1, pp. 07-28, 2015

DOI: https://doi.org/10.28998/2179-5428.20150102 


\title{
A construção de usinas hidrelétricas e as disputas assimétricas para usos diversos dos espaços ambientais
}

podemos refletir sobre este debate através do conceito de "campo ambiental", entendido como uma "arena de confronto" na qual diferentes ideias, valores e representações sobre o ambiente se opõem e disputam reconhecimento e legitimidade.

Palavras-Chaves: Hidrelétrica; Assimetria; Desenvolvimento Sustentável; Irapé; Injustiça Ambiental

\begin{abstract}
Since 1970 diverse social groups embraced the sustainable development paradigm which lies in the belief of accommodation between economic growth and environmental protection. Guided by the naturalizing effect of this belief, the sustainable development concept emerges as a new ideology/utopia that asserts the endurance of the developmentalists' premises of the capitalist production model. However, this compromising idea presents many contradictions, including the social asymmetries on the appropriation of nature and the process of environmental injustice caused by construction of hydroelectric power plants. Based on the case study of the Irape hydropower project built in the Jequitinhonha Valley this paper seeks to demonstrate that the dispute for environmental spaces is a direct result of the conflict between different ideas about the appropriation of nature. We also establish that these disputes even resonate in the unequal distribution of these spaces, producing social externalities and environmental injustices. Anchored in the recognition of the plurality of these logics we can frame this debate through the concept of the "environmental field" understood as a conflict arena in which different ideas, values and representations about the environment are opposed and fight for recognition and legitimacy.
\end{abstract}

Keywords: Hydroelectric; Asymmetries; Sustainable Development; Irapé; Environmental Injustice 


\section{A obra faraônica e a incapacidade de enxergar a diversidade cultural $^{2}$}

A construção da Usina Hidrelétrica de Irapé (UHE Irapé) desde sua concepção foi um projeto controverso. Surgiu com o estudo denominado Aproveitamento do Potencial Energético da Bacia do Jequitinhonha, realizado pelo consórcio Canambra Consulting Engineers Limited, no início da década de $60 .{ }^{3}$ Todavia, o aprofundamento deste estudo só ocorreu em 1987, através dos Estudos de Inventário da Bacia do Jequitinhonha elaborado pela CEMIG. Neste levantamento, foi feita uma divisão da bacia hidrográfica em 16 projetos hidrelétricos: 11 no rio Jequitinhonha e 5 no rio Araçuaí (RIBEIRO, 1993).

O primeiro projeto concretizado do inventário foi a usina de Itapebi, em Salto da Divisa-MG, que recebeu a licença de operação em 2002. O segundo barramento do rio Jequitinhonha ocorreu com a construção de Irapé, pela própria CEMIG, cuja barragem possui 208 metros de altura, a mais elevada do país. $O$ empreendimento tem a garantia física/energia assegurada de 206,30 MW e se encontra entre os municípios de Berilo e Grão Mogol (ANEEL, 2015).

A energia elétrica produzida pela usina não foi destinada ao vale do Jequitinhonha, pois, conforme já constava no próprio EIA/RIMA do empreendimento, a região carece de outros fatores atrativos para a instalação de indústrias, como por exemplo, estradas, mão-de-obra especializada etc. (ENERCONSULT, 1993).

Ao todo foram inundados 137,16 $\mathrm{km}^{2}$, dos quais $90 \mathrm{Km}^{2}$ eram de vegetação nativa, predominantemente do bioma cerrado. $\mathrm{O}$ remanso do reservatório atinge cerca de $100 \mathrm{~km}$ do rio Jequitinhonha e $50 \mathrm{~km}$ do rio Itacambiruçu. Aproximadamente 1.200 famílias de 47 comunidades

\footnotetext{
2 Este artigo foi devidamente atualizado, mas, tem como base a apresentação realizada no GT-2 da ANPPAS de 2006, fruto da dissertação defendida no mestrado em sociologia da UFMG, que contou com auxílio financeiro da Capes.

${ }^{3}$ O Consórcio Canambra surgiu através de uma ação conjunta do governo brasileiro e do Banco Mundial. Este consórcio era composto por empresas canadenses, americanas e brasileiras. Os estudos elaborados pelo Canambra fundamentaram o planejamento energético do Brasil e subsidiaram os planos de desenvolvimento econômico do país: Programa de Ação Econômico do Governo (PAEG) de 1964 a 1966 e o Plano Estratégico de Desenvolvimento (PED) de 1968 a 1970 (GOMES et al., 2003).
} 


\section{A construção de usinas hidrelétricas e as disputas assimétricas para usos diversos dos espaços ambientais}

distribuídas às margens desses rios e de seus afluentes tiveram suas terras inundadas. Além de Berilo e Grão Mogol, os demais municípios que tiveram parte de seus territórios cobertos pela água do reservatório, são: Turmalina, Botumirim, Cristália, José Gonçalves de Minas e Leme do Prado, ${ }^{4}$ todos no vale do Jequitinhonha, estado de Minas Gerais (FEAM, 2003 e 1997).

Quadro 1: Municípios e seus territórios inundados pela UHE Irapé

\begin{tabular}{|c|c|c|}
\hline Municípios & $\begin{array}{c}\text { Área da Unidade } \\
\text { Territorial * }\end{array}$ & $\begin{array}{c}\text { Área das Terras } \\
\text { Inundadas }\end{array}$ \\
\hline Cristália & $840,67 \mathrm{Km}^{2}$ & $38,00 \mathrm{Km}^{2}$ \\
\hline $\begin{array}{l}\text { José Gonçalves de } \\
\text { Minas }\end{array}$ & $382,86 \mathrm{Km}^{2}$ & $25,96 \mathrm{Km}^{2}$ \\
\hline Botumirim & $1.571,80 \mathrm{Km}^{2}$ & $25,66 \mathrm{Km}^{2}$ \\
\hline Grão Mogol & $3.889,62 \mathrm{Km}^{2}$ & $15,84 \mathrm{Km}^{2}$ \\
\hline Turmalina & $1.153,09 \mathrm{Km}^{2}$ & $9,99 \mathrm{Km}^{2}$ \\
\hline Berilo & $586,75 \mathrm{Km}^{2}$ & $6,87 \mathrm{Km}^{2}$ \\
\hline Leme do Prado & $281,31 \mathrm{Km}^{2}$ & $4,91 \mathrm{Km}^{2}$ \\
\hline TOTAL & $8.706,10 \mathrm{Km}^{2}$ & $127,23 \mathrm{Km}^{2 * * *}$ \\
\hline
\end{tabular}

${ }^{*}$ Dados coletados pelo Censo 2000/IBGE.

** Dados declarados pelo empreendedor na Audiência Pública, em Acauã, 1997. Porém, para efeito de comparação, os números foram transformados de hectares para $\mathrm{Km}^{2}$.

*** Este número, apresentado na Audiência Pública de Acauã, contrapõe-se ao número de 137,16 km² , oficializado pela Fundação Estadual de Meio Ambiente - FEAM.

A construção da usina hidrelétrica de Irapé inundou importantes áreas utilizadas pela agricultura familiar local, as chamadas áreas de vazante, porções de terras que se encontram às margens dos rios. Como o vale do Jequitinhonha possui um baixo índice pluviométrico, concentrado entre os meses de novembro e fevereiro, as áreas de vazante surgem no período da seca, geralmente entre março e outubro, quando o rio tem sua vazão diminuída. As variações sazonais do volume d'água no leito do rio

\footnotetext{
${ }^{4}$ Em Leme do Prado vive a comunidade negra rural de Porto Corís, o primeiro remanescente quilombola de Minas Gerais, oficialmente reconhecido pela Fundação Cultural Palmares/Ministério da Cultura (Publicado no Diário Oficial da União em 26/01/1998). Sobre as características sócio-econômicas de Porto Corís, ver Santos (2001) e FCP \& UFAL (1997).
} 
permitem que essas áreas sejam naturalmente fertilizadas, sem a necessidade da adição de adubos ou corretivos para o solo. Com isso, a apropriação dessas terras se torna de extrema importância para as comunidades ribeirinhas, pois, são nelas que as famílias desempenham a agricultura de base familiar no período mais crítico do ano, na época da seca.

Com o represamento do rio, o fluxo normal de sedimentos orgânicos que fertilizam as margens do Jequitinhonha, também à jusante, perdeu esta característica natural. Desta maneira, tanto à montante como à jusante, as áreas ribeirinhas foram inviabilizadas para a agricultura. À jusante, centenas de famílias foram prejudicadas desde o processo de construção da usina, uma vez que elas dependiam do rio Jequitinhonha para diversos fins, inclusive para abastecimento de água (FEAM, 2002). Moradores ribeirinhos relataram a perda de suas vazantes a mais de $60 \mathrm{~km}$ abaixo do eixo da barragem, descendo o rio Jequitinhonha até o município de Coronel Murta. Esses ribeirinhos sequer foram reconhecidos pela CEMIG (ZHOURI \& OLIVEIRA, 2012; ZHOURI, OLIVEIRA \& LASCHEFSKI, 2011).

O parecer técnico da FEAM já sinalizava a iminência dessa perda, uma vez que previa durante o funcionamento da UHE Irapé a ocorrência de uma variação média anual do nível de água do reservatório em torno de 10 metros (cotas $510 \mathrm{~m}$ e $500 \mathrm{~m}$ ). Indicava, inclusive, a possibilidade de ocorrer casos extremos em que a variação do nível d'água poderia atingir mais 39 metros de altura. Com essas variações associadas a outros fatores como: morfopedologia do rio, relevo do entorno e qualidade da água, por exemplo, o parecer indicava que se tornariam impraticáveis a navegação pluvial, as atividades de lazer e o turismo no reservatório e, também, a prática da agricultura também no seu entorno (FEAM, 1997).

Por estas e outras razões, a construção da usina de Irapé no Vale do Jequitinhonha impôs às famílias, tanto à montante quanto à jusante, uma mudança compulsória de seus modos de vida. Mesmo àqueles que optaram por permanecer próximos ao rio, no remanescente de suas propriedades atingidas, tiveram de se adequar ao novo ambiente formado e às restrições de uso do reservatório.

É importante ressaltar que as comunidades ribeirinhas atingidas possuíam características e especificidades socioculturais no que se refere à 


\section{A construção de usinas hidrelétricas e as disputas assimétricas para usos diversos dos espaços ambientais}

forte identidade com o local de moradia, às formas de apropriação e usos dos territórios e de seus recursos. Estes usos eram mediados por códigos morais, relações de parentesco e proximidade, o que configurava uma organização social particular, essencialmente relacionada à história das comunidades e ao território. ${ }^{5}$

Quadro 2: População dos municípios atingidos pela UHE Irapé

\begin{tabular}{|l|l|l|l|l|l|}
\hline \multicolumn{1}{|c|}{ Município } & Homens & Mulheres & Total & Urbana & Rural \\
\hline Berilo & 6.619 & 6.360 & 12.979 & 3.031 & 9.948 \\
\hline Botumirim & 3.550 & 3.284 & 6.834 & 3.306 & 3.528 \\
\hline Cristália & 2.777 & 2.806 & 5.583 & 2.595 & 2.988 \\
\hline Grão Mogol & 7.352 & 6.872 & 14.224 & 4.831 & 9.393 \\
\hline $\begin{array}{l}\text { José Gonçalves de } \\
\text { Minas }\end{array}$ & 2.381 & 2.315 & 4.696 & 783 & 3.913 \\
\hline Leme do Prado & 2.420 & 2.316 & 4.736 & 1.541 & 3.195 \\
\hline Turmalina & 8.037 & 7.618 & 15.655 & 10.158 & 5.497 \\
\hline \multicolumn{1}{|c|}{ TOTAL } & $\mathbf{3 3 . 1 3 6}$ & $\mathbf{3 1 . 5 7 1}$ & $\mathbf{6 4 . 7 0 7}$ & $\mathbf{2 6 . 2 4 5}$ & $\mathbf{3 8 . 4 6 2}$ \\
\hline \multicolumn{2}{|l|}{}
\end{tabular}

Fonte: Censo 2000 / Instituto Brasileiro de Geografia e Estatística - IBGE.

A formação do reservatório do empreendimento atingiu somente populações da área rural. Foram cerca de 1.200 famílias compulsoriamente deslocadas por causa da UHE Irapé, somando, aproximadamente, 5.000 pessoas (como consta no "Mapa de Acompanhamento do Licenciamento Ambiental - DIENE/FEAM - MG, 2005"). Se analisarmos quantitativamente o quadro 2, perceberemos que os 5.000 atingidos correspondiam à época a $13 \%$ da população rural dos 7 municípios afetados. Portanto, um número expressivo de pessoas que tiveram seus modos de vida diretamente alterados por causa das implicações oriundas da construção da usina hidrelétrica.

Apesar de estabelecer aqui números que quantificam a população rural dos municípios atingidos, tal como é definida pelos critérios do Instituto Brasileiro de Geografia e Estatística (IBGE), existem outras implicações que devem ser consideradas. Primeiramente, o uso do termo

${ }^{5}$ Para melhor compreensão da distinção ambiental e a correlação do uso da terra pelos lavradores locais, ver Santos, Galizoni \& Ribeiro (2002); Galizoni (2000); Ribeiro (1993). 
genérico 'população rural', neste trabalho, está relacionado ao modo de vida específico dos moradores da região estudada (Alto e Médio Jequitinhonha) e não implica na existência de uma homogeneidade social, econômica e/ou cultural.

Fazemos esta distinção em decorrência de um problema muito comum nos licenciamentos ambientais. Refere-se à tentativa de homogeneização da diversidade sociocultural das comunidades que, de alguma forma, serão deslocadas pela implantação de hidrelétricas. Os EIA/RIMAs reduzem as diversidades, aplicando-lhes uma ideia de homogeneização cultural.

Nos estudos da UHE Irapé, por exemplo, a Enerconsult Engenharia Ltda., empresa de consultoria contratada pela CEMIG para realizar tal estudo, caracterizava a população local com "baixo grau de diferenciação social" (ENERCONSULT, 1993, p.52). Na Audiência Pública sobre a UHE Irapé, ocorrida no distrito de Acauã, município de Leme do Prado, em 1997, o representante desta empresa declarou ainda que na área destinada ao reservatório se encontravam: "600 unidades produtivas, 3.000 pessoas e 400 casas". Contudo, diferente da concepção homogênea e mercantilista de "baixo grau de diferenciação social" e de "unidades produtivas", os atingidos chamavam a atenção dos:

[...] Senhores que não conhecem a terra norte mineira, presta atenção nessa história que ela é toda verdadeira. É tudo feito com o povo e muitas comunidades, pesquisa de vários dias pra descobrir a verdade [...] É tudo lugar sadio, onde nós fomos criados, nascemos e crescemos e estamos desde os avô mais recuado [...] Se engana direitinho quem pensa que é tudo igual, em cada banda do rio cada um é cada qual. Cada qual tem seu sistema de carpir, plantar e colher, os jeitos são diferentes, não é fácil de entender. [...] Se engana quem pensa que o povo todo é um só. [...] Eles [empreendedor] acaba com as diferença, ajunta os ateu com os crente, ajunta os forte com os fraco, os de dente com os sem dente [...] (CORDEL DOS ATINGIDOS, 1997). 


\section{A construção de usinas hidrelétricas e as disputas assimétricas para usos diversos dos espaços ambientais}

A falta de elementos indicativos sobre a diferenciação cultural dos moradores do vale do Jequitinhonha e o uso de dados genéricos, segundo uma lógica homogeneizante da forma de vida dessas famílias, foram motivos de críticas aos estudos contratados pela CEMIG, também por parte do Ministério Público Federal:

A trama da lavoura de coivara e suas implicações sócio-econômicas-ambientais revelou-se complexa demais para o RIMA da projetada UHE Irapé, pois ela articula terra, lavoura, cultura, sustento e meio ambiente. Ficou mais fácil chamar de lavoura de subsistência de baixa produtividade, aplicar uma norma geral desqualificadora sobre aquilo que se desconhecia (MINAS GERAIS, 2001, p.27).

A partir destas considerações e do acompanhamento de outros processos de licenciamento no Brasil, podemos afirmar que estudos e debates relacionados ao licenciamento ambiental de hidrelétricas, em sua maioria, promovem a redução da diversidade sociocultural e simplificam sua complexa organização social e territorial através do uso recorrente do conceito de "atingido". Conforme esclarece Vainer (2008), a noção de atingido não é uma definição meramente técnica e/ou econômica, ela está em constante disputa:

[...] estabelecer que determinado grupo social, família ou indivíduo é, ou foi, atingido por certo empreendimento significa reconhecer como legítimo - e, em alguns casos, como legal - seu direito a algum tipo de ressarcimento ou indenização, reabilitação ou reparação não pecuniária (VAINER, 2008, p.40).

[...] ainda hoje, porém, em várias circunstâncias, assiste-se à permanência das concepções e estratégias territoriais-patrimonialistas, que buscam circunscrever o problema a duas e exclusivas dimensões: o território atingido é concebido como sendo a área a ser inundada e a população atingida é 
constituída pelos proprietários fundiários da área a ser inundada (VAINER, 2008, p.43. Grifos originais).

Assim, por um lado, o conceito sugere o delineamento de um alvo, de um objeto a ser transformado pela lógica do mercado global. Essa concepção enxerga não só o "atingido", mas também a natureza como entraves ao "desenvolvimento", portanto, inertes e passíveis de deslocamento compulsório. Conforme afirma Acselrad (1991, p.65):

Além de desqualificar os grupos sociais atingidos enquanto sujeitos políticos, o planejamento autoritário até aqui prevalecente nos grandes projetos hidrelétricos tende a equacionar enormes transformações socioambientais como se fossem redutíveis a simples operações patrimoniais com a propriedade jurídica. A área inundável é, assim, concebida como espaço de propriedade privada, e não de relações socioculturais diversificadas: desapropriam-se e indenizam-se os bens mas não se considera o universo não-mercantil da natureza e dos modos de vida.

Do lado oposto, apropriando-se do conceito, temos a tentativa de ressignificação do "atingido" como algo que não está passivo e que tenta, através do movimento (seja na formação de associações, movimentos sociais, oposições e lutas) não apenas resistir, mas, demonstrar sua existência e garantir seus direitos. E como nos diz Leff, a luta dos "atingidos" vai mais além, representando um movimento de re-existência. "Estas identidades têm-se configurado através de lutas de resistência, afirmação e reconstrução do ser cultural frente às estratégias de apropriação e transformação da natureza que promove e impõe a globalização econômica" (LEFF, 2003, p.5). ${ }^{6}$

${ }^{6}$ No original: "Estas identidades se han configurado a través luchas de resistencia, afirmación y reconstrucción del ser cultural frente a las estrategias de apropiación y transformación de la naturaleza que promueve e impone la globalización económica" (LEFF, 2003, p.5). 


\section{A construção de usinas hidrelétricas e as disputas assimétricas para usos diversos dos espaços ambientais}

Assim, através do uso do mesmo conceito, os "atingidos" buscam não apenas o reconhecimento, mas a legitimação da diferença, dos direitos culturais específicos e localizados, rompendo com a "homogeneização forçada da vida induzida pelo pensamento metafísico e a racionalidade modernizante" (LEFF, 2003, p.6). ${ }^{7}$ Para todos os efeitos, faço uso do conceito de atingido em conformidade com esta segunda definição.

\section{As disputas pela apropriação material e simbólica da natureza}

A partir do racionamento de energia imposto pelo governo federal em 2001, resultante do temido "apagão", isto é, de uma possível "crise" no abastecimento de energia elétrica, fundamentada ainda na esperança de uma elevada taxa de crescimento econômico do Brasil e na "falta" de produção neste setor, justificam-se medidas imediatistas em torno da construção de novas hidrelétricas propostas como a única solução para eximir o "risco" do "apagão" e promoção do desenvolvimento. Os diversos segmentos do setor elétrico também utilizam de argumentos desqualificadores e homogeneizadores, tanto dos lugares quanto dos seus habitantes, enquanto estratégia de continuidade ao projeto hidrelétrico. ${ }^{8}$

Desse modo, os argumentos para maiores investimentos em infraestrutura, em prol do chamado progresso, passaram a propor diante da sociedade, o "abrandamento" e a flexibilização das normas ambientais vigentes, em detrimento do efetivo cumprimento da legislação pertinente e de direitos constitucionais e específicos. A supressão da vegetação em áreas protegidas e o deslocamento de inúmeras famílias assumem, por exemplo, uma condição de consequência inevitável do "progresso". Em síntese, os discursos cristalizam a ideia de que a legislação ambiental contempla uma excessiva preocupação com as características ecológicas, sociais e culturais,

\footnotetext{
${ }^{7}$ No original: "[...] homogeneización forzada de la vida inducida por el pensamiento metafísico y la racionalidad modernizante" (LEFF, 2003, p.6).

${ }^{8}$ Faço uso da ideia de "setor elétrico", no sentido de aglutinar os atores atuantes e com possibilidades reais de estabelecerem seus propósitos no âmbito decisório do sistema brasileiro de produção de energia elétrica. Como exemplo, podemos citar agências e representantes governamentais (ANEEL, instituições financiadoras e Ministério das Minas e Energia) e barrageiros (empresários, indústrias de eletrointensivo, construtoras de hidrelétricas e fornecedoras de materiais para a construção e operação das hidrelétricas).
} 
constituindo, assim, em "empecilhos" à demanda de "crescimento" econômico do país.

Estes "alertas" funcionam como grandes barreiras à consolidação de uma política ambiental planejada, pois, o "risco iminente" implica sempre a adoção de políticas emergenciais que acabam sendo condescendentes com interesses exclusivos.

Dessa maneira, direitos constitucionais garantidos pela Constituição Brasileira (1988), principalmente, aqueles concernentes ao "meio ambiente ecologicamente equilibrado", proposto em seu artigo 225, estão sendo:

[...] eliminados sob a lógica de que eles constituem obstáculos ao livre funcionamento do mercado, restringindo assim o desenvolvimento e a modernização. Essa mesma lógica transforma os cidadãos/portadores de direitos nos novos vilãos da nação: inimigos das reformas desenhadas para encolher as responsabilidades do Estado. Assim, se registra uma inversão peculiar: o reconhecimento de direitos, considerado no passado recente como indicador de modernidade, torna-se símbolo de "atraso", um anacronismo que bloqueia o potencial modernizante do mercado (DAGNINO, 2004, p.106).

O pano de fundo desta questão está relacionado à ideia do "mito do desenvolvimento". ${ }^{9}$ Este pode ser entendido segundo uma lógica do imaginário ocidental, situado num eixo temporal que, progressivamente, vai-se seguindo rumo à uma meta "universalmente desejável", ao progresso e à modernidade. Nessa perspectiva, a economia assume o "locus principal da produção simbólica"' (SAHLINS, 1979, p. 232).

Não há lógica material separada do interesse prático e o interesse prático do homem na produção é simbolicamente instaurado. As finalidades assim

\footnotetext{
9 Uma análise mais detalhada sobre o mito do desenvolvimento pode ser
} encontrada em Furtado (2001); em Ribeiro, 2000; em Pádua (1999); entre outros. 


\section{A construção de usinas hidrelétricas e as disputas assimétricas para usos diversos dos espaços ambientais}

como as modalidades de produção vêm do lado cultural: os meios materiais da organização cultural assim como a organização dos meios materiais (SAHLINS, 1979, p. 228).

A lógica economicista imposta por um modelo hegemônico e linear, fundamentado no modo capitalista de produção, vem encontrando dificuldades em se manter, justamente por não introduzir diferentes significações às finalidades e modalidades de produção. Contudo, mesmo apresentando constantes fissuras, o "mito do desenvolvimento", após inúmeros processos de reativação, vem prevalecendo sobre suas sucessivas crises e recriando, em cada uma delas, uma nova adjetivação capaz de contribuir com sua manutenção (RIBEIRO, 2000). Dessa forma, a ideia do "desenvolvimento sustentável", refletindo certa preocupação com a conservação dos recursos naturais para as futuras gerações, surge como mais uma possibilidade de reverter mais uma crise capitalista. Desta vez, a proposta pretende compatibilizar desenvolvimento econômico e preservação ambiental.

Esta construção paradigmática foi incorporada por diversos segmentos que a transformaram na doxa ambiental dominante (CARNEIRO, 2003). Essa doxa "[...] é operada sob coações estruturais. E pode-se inclusive explicar em termos sociológicos aquilo que aparece como uma propriedade universal da experiência humana, a saber, o fato de que o mundo familiar tende a ser taken for granted" (BOURDIEU, 1990, p.157).

Guiados por esse "efeito de naturalização" da ideia de "compatibilidade", várias instâncias, principalmente a econômica, oportunamente puderam dar continuidade a sua caminhada rumo ao desenvolvimento "democrático", com respaldo ideológico de estarem sempre "respeitando" a natureza e os "interesses sociais".

Porém, a cada dia, tornam-se mais evidentes as contradições do modelo político-econômico fundamentado no jargão do "desenvolvimento sustentável". Isto porque o desenvolvimento, tal como é concebido, baseado na ideia de evolução, de progresso, tem como objetivo principal o crescimento econômico unilinear. Acredita-se que o aumento contínuo das forças produtivas seria a possibilidade de mitigar conflitos internos de cada sociedade, permitindo ainda a satisfação das demandas coletivas através de arranjos econômicos e políticos. Ademais, seria capaz também de 
"aumentar o controle humano sobre o espaço natural, nulificando os riscos ambientais advindos dos movimentos da ecosfera" (PÁDUA, 1999, p.18).

A contradição deste modelo está exatamente nessa ilusória possibilidade de "conservar" os "recursos naturais" para as futuras gerações. Como isso seria possível já que hoje esses "recursos" constituem a própria fonte propulsora do atual modelo de desenvolvimento?

A atitude ingênua consiste em imaginar que problemas dessa ordem serão solucionados necessariamente pelo progresso tecnológico, como se a atual aceleração do progresso tecnológico não estivesse contribuindo para agravá-los (FURTADO, 2001, p.12).

De acordo com Dupuy (1980, p.16), "na guerra implacável a que se entregam os capitalistas, cada um tem interesse em investir em técnicas cada vez mais capitalísticas que permitem produzir mais, a um menor custo". Os maiores custos não são incorporados nas contas empresariais, e, geralmente, quem paga por eles acaba sendo os ecossistemas, as comunidades rurais e minorias étnicas que participam diversamente do modo de vida urbano-industrial.

\section{hidrelétricas \\ A apropriação assimétrica do espaço ambiental através das}

Ao relacionar a discussão anterior com o objeto de pesquisa deste artigo, consideramos que a lógica da construção de hidrelétricas constitui um bom exemplo da contradição inerente ao conceito de desenvolvimento sustentável.

A implantação de hidrelétricas, vista como uma fonte de energia "limpa", "barata" e "abundante", 10 requer a ocupação de "espaços

\footnotetext{
${ }^{10} \mathrm{O}$ mito de que a hidrelétrica é uma fonte barata de produção de energia ocorre porque a maioria dos projetos não incorpora, em seus custos finais, os danos sociais e ambientais provocados pelo empreendimento. As indenizações e programas diversos de mitigação e compensação desconsideram as especificidades e funções ecológicas das matas a serem inundadas, assim como os modos de vida e padrões culturais das comunidades atingidas. Além disso, os baixos custos das barragens no Brasil resultam de uma política de subvenções. Os subsídios e
} 


\section{A construção de usinas hidrelétricas e as disputas assimétricas para usos diversos dos espaços ambientais}

ambientais" que não estão vazios. Conforme estabelece Martínez-Alier (2002), os "espaços ambientais" correspondem a um determinado espaço geográfico efetivamente utilizado por um grupo social, seja na obtenção dos recursos naturais, ou na destinação dos efluentes. Inúmeros atributos ecológicos e sociais são constituintes desses "espaços" e, quando o reconhecimento destes é reivindicado, ele se defronta com a concepção linear do modelo capitalista de produção que, segundo Leff, desnaturalizou a natureza "para convertê-la em recurso e inseri-la no fluxo unidimensional do valor e da produtividade econômica" (LEFF, 2003, p.3). ${ }^{11}$ Estamos falando de um modelo que enxerga a natureza como recurso, como uma possibilidade de acumulação de riquezas e que, obrigatoriamente, marginaliza outros segmentos que não compartilham do modo de vida intrínseco a este modelo. Nesse sentido, as outras concepções de uso e ocupação são classificadas como "entraves" ou "barreiras" ao desenvolvimento econômico deste modelo hegemônico.

Assim, por demandar a ocupação de enorme quantidade de "espaço ambiental", a construção das hidrelétricas implica na exclusão e na assimetria dos diferentes usos e da ocupação deste "espaço" (LEFF, 2001; MARTÍNEZ-ALIER, 2002).

A imposição da construção da UHE Irapé, com fins homogeneizantes, exclusivos para suprir a energia elétrica demandada por um determinado segmento da economia industrial, ${ }^{12}$ expropria os diversos modos de apropriação, uso e significação dos "espaços ambientais" ocupados por comunidades atingidas, que:

financiamentos oferecidos pelo Estado dispensam investimentos maiores por parte das empresas e tornam empreendimentos que, em sua concepção eram economicamente inviáveis, em obras possíveis. Como é o caso da Usina Hidrelétrica de Irapé. Graças ao aporte de mais R\$ 100 milhões do governo estadual em dividendos da empresa é que foi possível viabilizar economicamente a obra.

${ }^{11}$ No original: "para convertirla en recurso e insertarla en el flujo unidimensional del valor y la productividad económica" (LEFF, 2003, p.3).

$12 \mathrm{Um}$ dos maiores consumidores de energia provem de setores da indústria eletrointensiva (alumínio, ferro-ligas, siderurgia, papel, celulose, entre outros). Conforme dados apresentados por Bermann (2003), a energia elétrica incorporada nestes produtos já representava, em 2000, 7,8\% do consumo de eletricidade no país. 
[...] não só perdem a base material de sua existência, as condições ambientais apropriadas ao seu modo de produção - terras férteis agricultáveis, as beiras dos rios, as nascentes, etc -, como perdem também suas referências culturais e simbólicas, as redes de parentesco estabelecidas no espaço, a memória coletiva assentada no lugar etc. (ZHOURI \& OLIVEIRA, 2005, p.51).

A partir deste exemplo, queremos afirmar que, de um lado, existe a disputa por um "espaço" que pretende ser ocupado para construção de uma usina hidrelétrica cujo objetivo final é fornecer insumos energéticos às indústrias, conforme a demanda de crescimento econômico-industrial do país. Todavia, o que pode ser visto apenas como um possível "espaço vazio" interessante aos anseios mercadológicos, adquire significação social distinta para outros agentes que veem naquele "espaço" fragmentos de vegetação nativa com funções ecológicas vitais para a proteção da biodiversidade local. Do mesmo modo, podemos encontrar neste mesmo "espaço", uma diversidade de comunidades ribeirinhas dependentes de suas atribuições ecológicas para manutenção de seus modos de vida. Pescadores, agricultores, quilombolas e indígenas que dependem dos rios para sua sobrevivência, e que constroem socialmente diferentes concepções deste mesmo "espaço".

O que queremos dizer é que a luta pela ocupação do "espaço ambiental", num contexto mais amplo, traz confrontos de (di)visão, por exemplo, entre "ambientalistas" que vislumbram a gestão daquele "espaço", preservacionistas que tentam conservar intactas as matas a serem destruídas pela formação do reservatório, empreendedores que visam lucrar com mais essa atividade comercial, Ministérios Públicos que "tentam" fazer valer a legislação e impedir a supressão dos ecossistemas e dos direitos sociais das famílias atingidas, políticos que tentam angariar os méritos das obras justificando-as como impulsos econômicos redentores para a localidade e, por fim, existem inúmeras comunidades que reivindicam o respeito às suas diferenças e a manutenção das sustentabilidades em suas diversidades. Enfim, com esse exemplo, é possível perceber a disputa por "espaços ambientais" como reflexo do conflito de várias vertentes pela apropriação da natureza. 


\section{A construção de usinas hidrelétricas e as disputas assimétricas para usos diversos dos espaços ambientais}

Contudo, "os cortes analíticos centrados no mercado são incapazes de reconhecer a diversidade de espaços sociais de não-mercado" (ACSELRAD, 1995). O atual modelo de desenvolvimento tenta simplificar a pluralidade dos usos, fundada nos potenciais da natureza e da cultura, a uma dimensão única, referente à racionalidade econômica convencional que concebe o ambiente como custo do processo econômico (LEFF, 2001; SACHS, 2000). Com isso, temos de um lado, a natureza apropriada como significados da reprodução do capital e, do outro, significados da reprodução das sociedades (O'CONNOR, 1998).

Os sentidos que são dados para os usos destes "espaços" manifestam o caráter conflitivo da questão ambiental, cujos atores participam de uma luta política pela:

Redistribuição do poder sobre os recursos territorializados, pela legitimação/deslegitimação das práticas de apropriação da base material das sociedades e/ou de suas localizações. As lutas por recursos ambientais são, assim, simultaneamente lutas por sentidos culturais (ACSELRAD, 2004, p.19).

Através da lógica plural de apropriação da natureza, o conceito de "campo ambiental", inspirado na noção bourdiana de campo, agrega um confronto entre representações e classificações enunciadas por segmentos sociais distintos (BOURDIEU, 2002; ZHOURI, 2001). Este "campo ambiental" é constituído por empreendedores, órgãos públicos, entidades ambientalistas, comunidades atingidas, assessorias, empresas de consultoria, empresas de construção civil, fabricantes de equipamentos (geradores, turbinas, pontes rolantes, tubulações, motores elétricos, transformadores, comportas), empresas que demandam alta quantidade de energia (alumínio, cobre, níquel, chumbo e aços especiais), além daqueles agentes que procuram angariar os "méritos" políticos da obra e que procuram se beneficiar dos investimentos do setor elétrico.

Neste sentido, considero que no licenciamento ambiental da UHE Irapé houve uma disputa em torno da intervenção humana na natureza, regulamentada por um conjunto de leis que estruturou as relações e conflitos decorrentes deste confronto. Destarte, o licenciamento se 
apresentou como um instrumento de controle e formalização das "regras do jogo", cujo objeto da disputa era a apropriação material e simbólica da natureza.

Portanto, o licenciamento ambiental de Irapé funcionou como mecanismo de perpetuação da ocupação assimétrica das terras da região, uma vez que, as avaliações normativas não ocorreram em seus devidos momentos e, quando aconteceram, privilegiou-se sempre a construção da usina. Como não houve qualquer tipo de discussão com a população local quanto à possibilidade de construir fontes alternativas para suprir o objetivo primevo (geração de energia), inúmeras famílias ribeirinhas foram excluídas do chamado "projeto de desenvolvimento".

Os mecanismos flexibilizantes que fazem dos processos de licenciamento, ${ }^{13}$ tais como: as medidas mitigadoras, as condicionantes, termos de ajustamento de conduta, de acordo e de compromisso, funcionam como subterfúgios de uma política de adequação cujos pressupostos desenvolvimentistas conduzem toda uma justificativa de não cumprimento da legislação ambiental e dos direitos humanos primordiais. Juntamente com as Audiências Públicas e EIA/RIMA's, representam instrumentos formais que, na prática, não viabilizam a democratização do uso do meio ambiente, uma vez que não há limites políticos às relações de mercado intrinsecamente desiguais.

Toda essa problemática ocorre devido a falta de cumprimento da legislação vigente. Os debates efetuados por aqueles que são responsáveis pela concessão das licenças ambientais que, regimentalmente, deveriam se referir à magnitude das interferências socioambientais provocados pelos empreendimentos, são esvaecidos pelo discurso político-econômico de empreendedores e governantes, e são assumidos segundo a lógica econômica do "desenvolvimento" do Estado, seja através da geração de impostos, empregos e investimentos que tal obra "poderá" propiciar, e/ou até mesmo de possíveis prejuízos financeiros para os empreendedores, caso não obtenham a licença ambiental requerida. Tudo isto é fruto do licenciamento ambiental atualmente realizado no Brasil. Este é desenhado a partir do que podemos chamar de "paradigma da adequação ambiental" (ZHOURI, LASCHEFSKI \& PEREIRA, 2005), no qual o empreendimento é

13 Para uma análise sobre os mecanismos flexibilizantes no processo de licenciamento da usina hidrelétrica de Irapé, consultar Zucarelli (2011). 


\section{A construção de usinas hidrelétricas e as disputas assimétricas para usos diversos dos espaços ambientais}

prioritário, inquestionável e inexorável. Assim, o licenciamento tem por tarefa tornar a obra possível do ponto de vista de algumas normas ambientais, desde que estas exigências não inviabilizem o empreendimento.

Como resultado, as decisões políticas construídas a partir de negociações, pressões e coerções, deixam de contemplar uma discussão acerca das potencialidades sociais, culturais e ecológicas, para privilegiar decisões baseadas em condicionantes pró-mercantis. Consequentemente, são geradas externalidades sociais e ambientais que perpetuam as assimetrias sociopolíticas e as injustiças ambientais.

\section{Referências Bibliográficas}

ACSELRAD, Henri. Internalização de custos ambientais - da eficácia instrumental à legitimidade política. Cadernos INPUR/UFRJ. Rio de Janeiro. Ano IX, no 1/4, jan/dez, p.13-27, 1995.

ACSELRAD, Henri. Planejamento Autoritário e Desordem Socioambiental na Amazônia: crônica do deslocamento de populações em Tucuruí. Revista Administração Pública, (4), nº 25, p. 53-68, out/dez de 1991.

ACSERALD, Henri. As práticas espaciais e o campo dos conflitos ambientais. In: ACSERALD, H. (org.). Conflitos Ambientais no Brasil. Rio de Janeiro: Relume Dumará \& Fundação Heirinch Böll, 2004.

ANEEL, 2015. Banco de Informações de Geração. Disponível em http://www.aneel.gov.br/aplicacoes/capacidadebrasil/energiaassegurada.as p. Acesso em: 24 mai. 2015.

BERMANN, Célio. Indústrias Eletrointensivas e Auto-produção: propostas para uma política energética de resgate do interesse público. São Paulo: USP, 2003. Disponível em: www.provedor.nuca.ie.ufrj.br/provedor/biblioteca/investimento. Acesso em: 18 jul. 2005. 
BOURDIEU, Pierre. Espaço Social e Poder Simbólico. In: BOURDIEU, P. Coisas Ditas. São Paulo: Brasiliense, 1990.

BOURDIEU, Pierre. O Poder Simbólico. 5ª ed., Rio de Janeiro: Bertrand Brasil, 2002.

CARNEIRO, Eder Jurandir. Modernização Recuperadora e o Campo da Política Ambiental em Minas Gerais. 2003. Tese (Doutorado em Ciências Humanas: Sociologia e Política) - FAFICH/UFMG, Belo Horizonte, 2003.

CORDEL DOS ATINGIDOS. Romance de Irapé. Vale do Jequitinhonha-MG, 1997.

DAGNINO, Evelina. ¿Sociedade civil, participação e cidadania: de que estamos falando? In: MATTO, D. (Coord.). Políticas de ciudadanía y sociedad civil en tiempos de globalización. Caracas: FACES, Universidad Central de Venezuela, 2004.

DUPUY, Jean-Pierre. Introdução à Crítica da Ecologia Política. Rio de Janeiro: Civilização Brasileira, 1980.

ENERCONSULT, Engenharia Ltda. Estudos de Impacto Ambiental e Relatório de Impacto Ambiental. Dezembro de 1993, Belo Horizonte.

FUNDAÇÃO CULTURAL PALMARES - FCP \& UNIVERSIDADE FEDERAL DE ALAGOAS - UFAL. Relatório de identificação da comunidade negra rural de Porto Corís, município de Leme do Prado - MG. Novembro de 1997.

FUNDAÇÃO ESTADUAL DO MEIO AMBIENTE - FEAM. Parecer Jurídico AJU/FEAM. Processo 094/1994/002/2001, 22 de abril de 2002, Belo Horizonte.

FUNDAÇÃO ESTADUAL DO MEIO AMBIENTE - FEAM. Parecer Técnico DICAF nำ57, 1997, Belo Horizonte.

FUNDAÇÃO ESTADUAL DO MEIO AMBIENTE - FEAM. UHE Irapé: Acompanhamento do Cumprimento das determinações do Termo de 


\section{A construção de usinas hidrelétricas e as disputas assimétricas para usos diversos dos espaços ambientais}

Acordo firmado com o Ministério Público em 5-7-2002 (LI concedida em 264-2002), 01 de abril de 2003, Belo Horizonte.

FURTADO, Celso. O Mito do Desenvolvimento Econômico. $3^{\mathbf{a}}$ ed., Rio de Janeiro: Paz e Terra, 2001.

GALIZONI, Flávia Maria. A Terra Construída: Família, Trabalho, Ambiente e Migrações no Alto Jequitinhonha, Minas Gerais. 2000. Dissertação (Mestrado em Antropologia Social) - FFLCH/USP, São Paulo, 2000.

GOMES, Antônio Claret S. et al. O Setor Elétrico. Rio de Janeiro: BNDES, 2003.

LEFF, Enrique. La Ecología Política en América Latina. Un campo en construcción. Reunión del Grupo de Ecología Política de CLACSO. Ciudad de Panamá, 17-19 marzo de 2003.

LEFF, Enrique. Saber Ambiental. 2aa ed., Petrópolis, RJ: Vozes, 2001.

MARTÍNEZ-ALIER, Joan. Justiça Ambiental (local e global). In: CAVALCANTI, C. (org.). Meio Ambiente, Desenvolvimento Sustentável e Políticas Públicas. São Paulo: Cortez, 2002.

MINAS GERAIS. Ministério Público Federal. Ação Civil Pública. Processo 2001.38.0043661-9. Belo Horizonte: 21 $1^{\text {a }}$ Vara Federal, 18 de dezembro de 2001.

O'CONNOR, James. Capitalism, Nature, Socialism: A Theoretical Introduction. In: DRYZEK, J. S. \& SCHLOSBERG, D. (org.). Debating the Earth. The Environmental Politics Reader. Oxford: Oxford University press, 1998.

PÁDUA, José Augusto. Produção, Consumo e Sustentabilidade: o Brasil e o contexto planetário. Projeto Brasil Sustentável e Democrático. Rio de Janeiro: FASE, p. 11-48, 1999. 
RIBEIRO, Gustavo Lins. Cultura e Política no Mundo Contemporâneo paisagens e passagens. Brasília: Ed. da UnB, 2000.

RIBEIRO, Ricardo Ferreira. Campesinato: Resistência e Mudança - O Caso dos Atingidos por Barragens do Vale do Jequitinhonha. 1993. Dissertação (Mestrado em Sociologia) - FAFICH/UFMG, Belo Horizonte, 1993.

SACHS, Wolfgang. Development. The rise and decline of an ideal. Wuppertal Papers, Germany, nº 108, p. 3-29, august 2000.

SAHLINS, Marshall. Cultura e Razão Prática. Rio de Janeiro: Zahar Editores, 1979.

SANTOS, Ana Flávia Moreira Santos. A Comunidade de Porto Corís e os Aspectos Socioeconômicos do Processo de Licenciamento da UHE Irapé - Vale do Jequitinhonha - MG. In: MPF.1998-2002b. Procedimento Administrativo Cível no08112.001180/98-04, 2001.

SANTOS, Ana Flávia Moreira; GALIZONI, Flávia Maria \& RIBEIRO, Áureo Eduardo Magalhães. As Comunidades Tradicionais do Alto Jequitinhonha Face à Hidrelétrica de Irapé: Organização Sociocultural e Impactos. In: MPF. 1998-2002b. Procedimento Administrativo Cível no 08112.001180/98-04, Belo Horizonte, 2002.

VAINER, Carlos B. Conceito de "Atingido": uma revisão do debate. In: ROTHMAN, F.D. Vidas Alagadas: conflitos socioambientais, licenciamento e barragens. Viçosa-MG: Ed. UFV. 2008.

ZHOURI, Andréa \& OLIVEIRA, Raquel. Paisagens Industriais e Desterritorialização de Populações Locais: conflitos socioambientais em projetos hidrelétricos. In: ZHOURI, A.; LASCHEFSKI, K. \& PEREIRA, D. B. (Orgs). A Insustentável Leveza da Política Ambiental - desenvolvimento e conflitos socioambientais. Belo Horizonte: Autêntica, 2005.

ZHOURI, Andrea \& OLIVEIRA, Raquel. Experiências locais e olhares globais: desafios para os moradores do Vale do Jequitinhonha (MG) no campo ambiental. In: STEIL, C.A. e CARVALHO, I.C. (orgs.) Cultura, 


\section{A construção de usinas hidrelétricas e as disputas assimétricas para usos diversos dos espaços ambientais}

Percepção e Ambiente: Diálogos com Tim Ingold. Coleção Antropologia Hoje. São Paulo: Editora Terceiro Nome, 2012.

ZHOURI, Andrea, OLIVEIRA, Raquel \& LASCHEFSKI, Klemens. A supressão da vazante e o início do vazio: água e "insegurança administrada" no Vale do Jequitinhonha-MG. Anuário Antropológico: Dossiê Antropologia e Água. Brasília: Tempo Brasileiro, p.23-53, 2011.

ZHOURI, Andréa. Ambientalismo e Antropologia. Descentrando a categoria de movimentos sociais. Teoria e Sociedade. Belo Horizonte: UFMG, no 8 , p. 10-29, 2001.

ZHOURI, Andréa; LASCHEFSKI, Klemens \& PEREIRA, Doralice Barros (Orgs). A Insustentável Leveza da Política Ambiental - desenvolvimento e conflitos socioambientais. Belo Horizonte: Autêntica, 2005.

ZUCARELLI, Marcos Cristiano. O papel do Termo de Ajustamento de Conduta no licenciamento ambiental de hidrelétricas. In: ZHOURI, A. (org.). As tensões do lugar: hidrelétricas, sujeitos e licenciamento ambiental. Belo Horizonte: Editora UFMG. 2011.

Recebido em:

29.05.2015

Aprovado em:

26.06.2015 